\title{
Study of Date Palm Stem as Raw Material in Preparation of Activated Carbon
}

\author{
O. Houache¹, R. Al-Maamari², B. Al-Rashidi² ${ }^{2}$ and B. Jibril ${ }^{* 2}$ \\ ${ }^{1}$ Oman Polypropylene LLC, Sohar Industrial Port Complex, P.O. Box 277, PC 322, Falaj, Al-Qabail, Sohar, Oman \\ ${ }^{*}$ Department of Petroleum and Chemical Engineering, Sultan Qaboos University, P.O. Box 33, Al Khod, PC 123, Muscat, Oman
}

Received 14 February 2006; accepted 10 March 2007

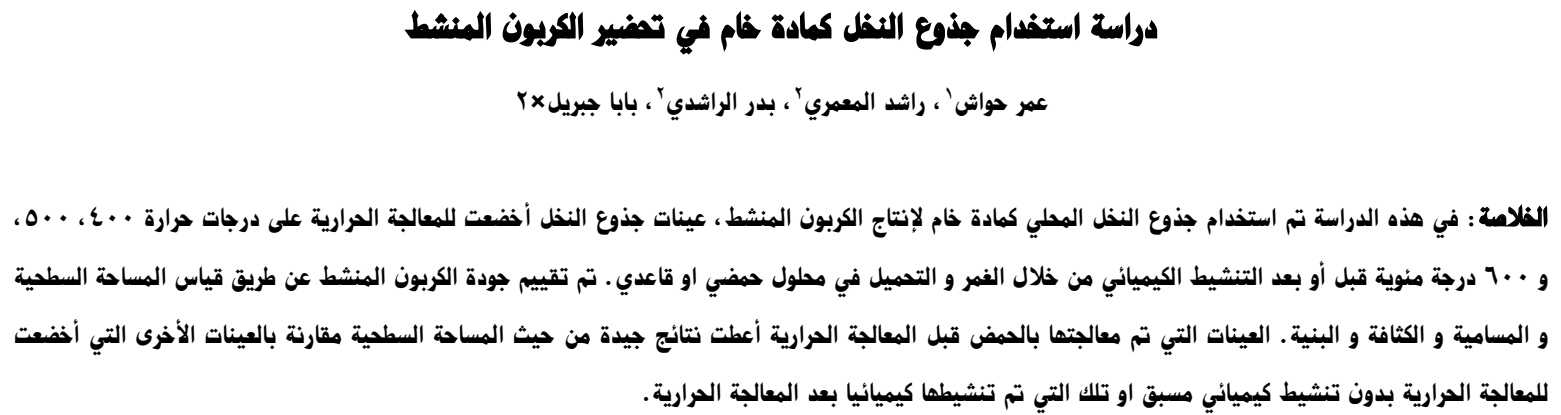

الهنرداه الهنتاهية: الكربون المنشط، التنشيط الكيميائي ، المساحة السطحية، البسامية، المسح بالبجهر الالكتروني ، جذوع النظل.

\begin{abstract}
Activated carbon adsorbent was prepared using Omani date palm tree stem as a precursor. Precursor samples were subjected to thermal treatment (at 400, 500 and $600{ }^{\circ} \mathrm{C}$ ) before or after impregnation with either $\mathrm{H}_{3} \mathrm{PO}_{4}(85 \mathrm{wt} \%$ ) or $\mathrm{KOH}$ (3 wt \%). The activated carbon obtained was characterized by BET (surface area and porosity), Gas Pycnometry (true density) and SEM (texture). Sample subjected to carbonization, without chemical activation, exhibited low surface areas $\sim 1.0$ $\mathrm{m}^{2} / \mathrm{g}$ at 400 and $500{ }^{\circ} \mathrm{C}$ and $124 \mathrm{~m}^{2} / \mathrm{g}$ at $600{ }^{\circ} \mathrm{C}$. Further treatment of such samples with either the acid or the base did not show improvement in surface area or other properties. Impregnations of the precursor with acid before carbonization significantly improved the surface area to as high as $1,100 \mathrm{~m}^{2} / \mathrm{g}$ at a carbonization temperature of $500{ }^{\circ} \mathrm{C}$. Thus, activated carbon with a moderate surface area could be produced from date palm stem using low carbonization temperature.
\end{abstract}

Keywords: Activated carbon, Chemical activation, BET surface area, Porosity, SEM, Date palm stem

\section{Introduction}

Activated carbon is used in many applications due to its adsorption capacity and large internal surface area. These applications are partly facilitated by the fact that the carbon precursor or the preparation conditions could be chosen to achieve a unique set of desirable properties (Luehrs, et al. 1998; Wartelle, et al. 2000 and Byrne, et al. 1997). Both naturally occurring and synthetic carbonaceous solid have been used (Gergova, et al. 1997; Jagtoyen, et al. 1992; Benaddi, et al. 2005; Yalcm, et al. 2000 and Nagano, et al. 2000). Though new synthetic precursors such as polymeric fibers and phenolic-resin have been reported to produce high surface area products (Cai, et al. 2004), agricultural wastes are increasingly being investigated as precursors (Wartlle, et al. 2004; Byrne, et al. 1997; Gergova, et al. 1996; Yalcm, 2000; Liou, 2004 and Carvalho, et al. 2003). Wood is the most favored source of activated carbon production (35\%) followed by coal (28\%), lignite (14\%), coconut shell (10\%), peat (10\%) and others (3\%) (Byrne, et al. 1977).

*Corresponding author’s e-mail: baba@squ.edu.om
Other lignocellulosic materials are also used which include nutshell (Wartelle, et al. 2000), apricot stones (Gergova, et al. 1996), rice husks (Yalcm, et al. 2000), cork waste (Carvalho, et al. 2003) and Dates pits (Caturla, et al. 1991; Molina-Sabio, et al. 1995; Wigmans, et al. 1989; Pelekani, et al. 2000 and Daifullah, et al. 2003).

The activating agents for preparing activated carbons can be used before or after carbonizing the raw materials. Some of the activating chemicals used in this process are boric acid, phosphoric acid, nitric acid and zinc chloride (Girgis, et al. 2002 and El-Hendawy, 2006). Once carbonization is achieved, the agents most widely used to activate the char are: steam, carbon dioxide, air or their combinations.

For example, when phosphoric acid is used as an activation chemical, the acid react with the lignocellulosics thermal decomposition products. This leads to bond weakening and formation of cross-linked structure. This reduces the release of volatile materials, restricts tar formation and loss of porosity (Teng, et al. 1998). In addition, the effect of the chemical agent leads to lower activation temperature and higher carbon yields (El-Akkad, et al. 19978). 
Based on the foregoing, we found it of interest to study different lignocellulosics materials as sources of activated carbon. Here, we report phosphoric acid and potassium hydroxide treatment of an Omani Date palm stem for preparing activated carbon. Oman and neighboring areas have millions of Date-palm-trees. Every year tons of Date palm tree trunk and stem are disposed off. This gives a free or low-cost, abundantly supplied precursor. As stated above, many workers have reported different aspects of production of activated carbon from Date pits, but to our knowledge, there are no reports on the use of Date-palmtree stem for such endeavor. The aim of this work was to prepare and characterize activated carbons from Date palm stems using chemical activation method which will contribute to further understanding the effects of activating chemical on the precursor's surface and other properties of the final products.

\section{Experimental Setup}

Activated carbon was prepared and characterized at the Petroleum and Chemical Engineering laboratory, Sultan Qaboos University, Oman.

\subsection{Sample Preparation}

Date palm stems were obtained from Nizwa region of Oman. They consist of a major outer part having softmesh and channel-like structure and inner hard part having longitudinal fibrous structure, as shown in Fig. 1. Samples were prepared by cutting slices of $1 \mathrm{~cm}$ thick from different parts of the stem before drying them in a muffle heater at $105^{\circ} \mathrm{C}$ for $24 \mathrm{hrs}$. Longer drying time did not show observable change in the samples weight. The dried samples were then used as precursors to obtain char and activated carbon. Before or after activation (impregnation) with either $\mathrm{H}_{3} \mathrm{PO}_{4}$ (85 wt \%) or potassium hydroxide $\mathrm{KOH}(3 w t \%)$ the weighed samples were carbonized in a muffle furnace under nitrogen atmosphere.

The chemical activation was accomplished by having $30 \mathrm{~g}$ of each dried sample immersed in $100 \mathrm{~g}$ of activating

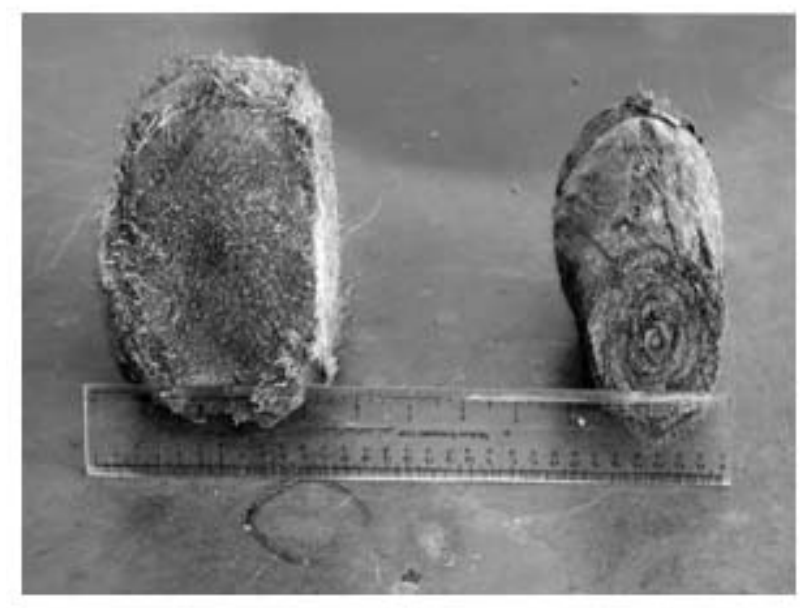

Figure 1. Sample of the date palm stem agents [either $\mathrm{H}_{3} \mathrm{PO}_{4}(85 \mathrm{wt} \%)$ or $\mathrm{KOH}(3 \mathrm{wt} \%)$ ] at room temperature then increasing the heating temperature to 85 ${ }^{\circ} \mathrm{C}$ at a heating rate of $15^{\circ} \mathrm{C} / \mathrm{min}$. The sample was exposed to this temperature for $3 \mathrm{hrs}$ before cooling to ambient temperature and left at rest for 16 hrs. These treated samples were then dried at $105^{\circ} \mathrm{C}$.

In all cases, carbonization was done under flow of nitrogen $(250 \mathrm{ml} / \mathrm{min})$. It took place by heating the samples at $100{ }^{\circ} \mathrm{C}$ for $20 \mathrm{~min}$ before raising the temperature in steps of $50^{\circ} \mathrm{C}$ up to the desired temperature (400, 500 or $600^{\circ} \mathrm{C}$ ). The final temperature was held constant for two hours before cooling the sample to ambient temperature.

Density and surface analysis took place after grounding and sieving the samples to sizes between 212 and 250 microns.

In the test, , the samples are represented based on the activation procedure as follows: $S$-untreated $=$ Date palm stem; $\mathrm{S}-\mathrm{C}=$ Carbonized Date palm stem; $\mathrm{S}-\mathrm{C}-\mathrm{H}_{3} \mathrm{PO}_{4}=$ Carbonization of Date palm stem followed by acid activation; $\mathrm{S}-\mathrm{C}-\mathrm{KOH}=$ Carbonization of Date palm stem followed by base activation; $\mathrm{S}-\mathrm{H}_{3} \mathrm{PO}_{4}-\mathrm{C}=$ Acid activation followed by carbonization of Date palm stem and $\mathrm{S}-\mathrm{KOH}-$ $C=$ Base activation followed by carbonization of Date palm stem.

\subsection{Characterization of Samples}

Samples of the activated carbon were characterized by physical adsorptions of $N_{2}$ at $77.4 \mathrm{~K}$, using a Quantachrome Autosorb 1C analyzer. The properties obtained are: (i) $B E T$ surface area $\left(S_{B E T}, \mathrm{~m}^{2} / \mathrm{g}\right.$ ), (ii) total pore volume from nitrogen held as liquid at $P / P^{o}=0.95$ $\left(V P, \mathrm{~cm}^{3} / \mathrm{g}\right)$ and (iii) average pore diameter. Prior to the analysis, samples were cleaned by heating them, under flow of helium, at $300^{\circ} \mathrm{C}$ for 3 hrs. Densities of the samples were measured by displacement of helium using a Quantachrome UltraPycnometer 1000. The textures of samples of the products were observed using SEM - scanning electron microscope (JEOL JSM 840A). It was equipped with an energy dispersive $X$-ray analyzer that allowed semi-quantitative analysis of solids.

\section{Results and Discussion}

The precursor was subjected to different carbonization times and activations and the decreases in sample weight were recorded. The char yield of Date palm stem was compared with those obtained from other cellulose materials such as almond shell and coconut shell, in Fig. 2. It could be observed that the char yielded from Date palm stem is substantially higher than that from other lignocelluloic sources (Al-Rashidi 2004). Carbonization without chemical impregnation of the precursor yielded char that exhibited surface areas of about $1.0 \mathrm{~m}^{2} / \mathrm{g}$ at 400 and 500 ${ }^{\circ} \mathrm{C}$. The area increased to $124 \mathrm{~m}^{2} / \mathrm{g}$ at $600{ }^{\circ} \mathrm{C}$. The yields were improved by impregnations of the precursor with either $\mathrm{H}_{3} \mathrm{PO}_{4}$ or $\mathrm{KOH}$ before carbonization. The surface area also increased. The base treatment increased the area 


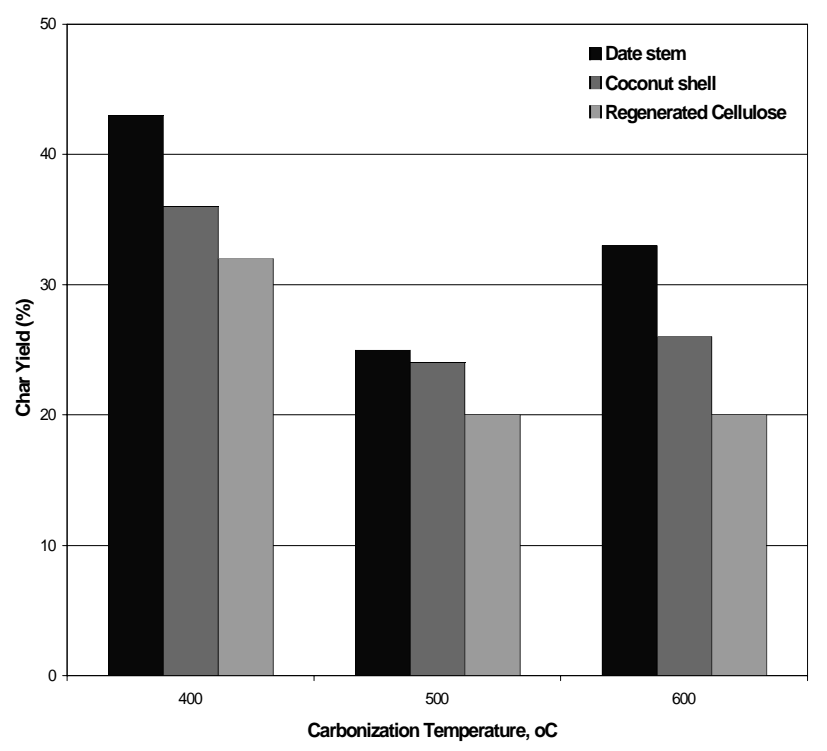

Figure 2. Comparison of char yields for different precursors at different carbonization temperature

Table 1. Surface area, acverage pore diameter, and total pore volume of samples prepared at different heat treatment

\begin{tabular}{|c|c|c|c|c|}
\hline & & & perature & 㒸C) \\
\hline & Sample & 400 & 500 & 600 \\
\hline & S-C & 0.0936 & 0.7700 & 119.0 \\
\hline ( $\mathrm{S}_{\mathrm{BET}}$, & $\mathrm{S}-\mathrm{C}-\mathrm{H}_{3} \mathrm{PO}_{4}$ & 1.2600 & 0.3610 & 31.50 \\
\hline $\left.\mathrm{m}^{2} / \mathrm{g}\right)$ & $\mathrm{S}-\mathrm{H}_{3} \mathrm{PO}_{4}-\mathrm{C}$ & 691.0 & 1100.0 & 632.0 \\
\hline & S-KOH-C & 27.80 & 29.40 & 94.70 \\
\hline & S-C & 539.0 & 295.0 & 28.20 \\
\hline $\begin{array}{l}\text { Avg. pore } \\
\text { diameter }\end{array}$ & $\mathrm{S}-\mathrm{C}-\mathrm{H}_{3} \mathrm{PO}_{4}$ & 104.0 & 67.00 & 41.40 \\
\hline diameter & $\mathrm{S}-\mathrm{H}_{3} \mathrm{PO}_{4}-\mathrm{C}$ & 36.90 & 41.60 & 37.30 \\
\hline & $\mathrm{S}-\mathrm{KOH}-\mathrm{C}$ & 45.90 & 50.70 & 36.00 \\
\hline & S-C & 0.0012 & & \\
\hline & & 6 & 0.00568 & 0.0839 \\
\hline$\left(\mathrm{V}_{\mathrm{P}}, \mathrm{cc} / \mathrm{g}\right)$ & $\mathrm{S}-\mathrm{C}-\mathrm{H}_{3} \mathrm{PO}_{4}$ & 0.0033 & 0.00061 & 0.0326 \\
\hline & $\mathrm{S}-\mathrm{H}_{3} \mathrm{PO}_{4}-\mathrm{C}$ & 0.6370 & 1.1500 & 0.5890 \\
\hline & S-KOH-C & 0.0320 & 0.0372 & 0.0852 \\
\hline
\end{tabular}

by one order of magnitude at 400 or $500{ }^{\circ} \mathrm{C}$, but led to an inferior product at $600{ }^{\circ} \mathrm{C}$, as shown in Table 1 . On the other hand, acid treatment improved the surface areas at all temperatures: $690.9,1101.0$ and $632.2 \mathrm{~m}^{2} / \mathrm{g}$ at 400,500 and $600{ }^{\circ} \mathrm{C}$ respectively. This suggests that by chemical treatment of Date palm stem, the chemistry of the carbonization was changed. Due to dehydration, different macromolecular networks were formed which resulted in promotion of cross linking of structure and suppression of tar formation during the carbonization (Attia, 1997).
Furthermore, the increase and decrease in surface areas with the chemical treatment, indicate the complex and interacting effects of different changes in the sample. Due to different degrees of interaction, some volatiles components may react and link to carbon structure, or other compounds could be formed thereby changing the product porosity and the extent of exposed surface area.

The characteristic of the product was further explored by measuring the true densities. Figure 3 shows increase in densities with increase in carbonization temperature. When the char formed was subjected to post-treatment with either acid or base, different behaviors were observed. For the char produced at $400^{\circ} \mathrm{C}$, impregnation with $\mathrm{KOH}$ exhibited a little decrease in density. However, at higher temperatures, there was an increase of the densi-

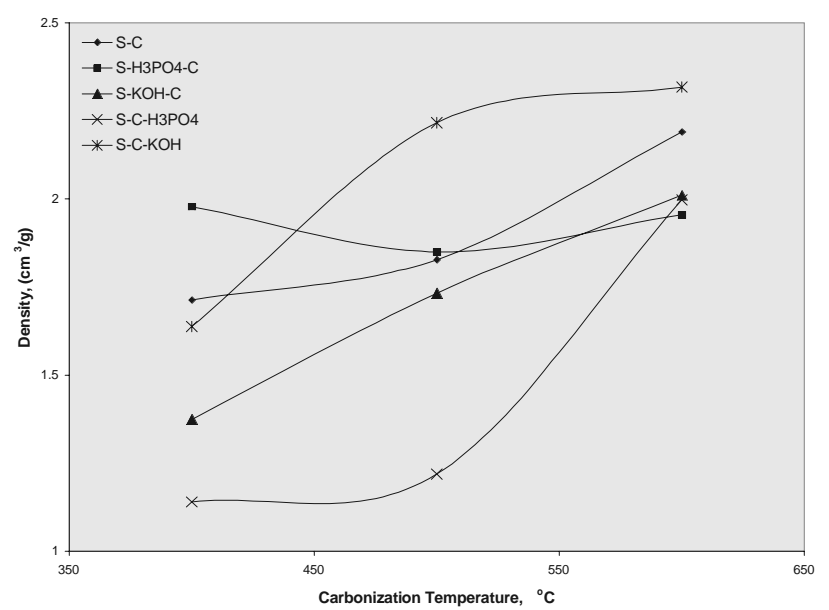

Figure 3. Density of different samples after carbonization

ty by 21.2 and $5.8 \%$ at 500 and $600{ }^{\circ} \mathrm{C}$ respectively. On the other hand, samples treated with acid, show a decrease in the densities; 33.5, 33.3 and $8.8 \%$ at 400,500 and 600 ${ }^{\circ} \mathrm{C}$ respectively. In all cases, the samples were treated to adjust the $p H$ of the water in which the char was suspended. Depending on the surface morphology of the char, the $\mathrm{KOH}$ may be binded with surface functional groups (Shih, et al. 2005). Such interactions would lead to corsslinking reactions with some of the volatiles thereby retaining them in the solid matrix. This would result into increase in the net mass of the sample, thereby increasing the density. Addition of $\mathrm{H}_{3} \mathrm{PO}_{4}$ on the other hand, may lead to dehydrogenation and release of gases, thereby decreasing the net mass and density of the char. Impregnation of the precursor prior to carbonization lead to partly physical diffusion of the chemical to the internal structures of the samples and partly chemical reaction with compound in the structure. Carbonization resulted into chars of different characteristics. Their differences decrease with an increase in the temperature (Fig. 3). All samples appear to converge to constant similar densities. This implies that the final products obtained may have similar true densities (Shih, et al. 2005).

The SEM micrographs of (a) Date palm stem and chars produced at (b) 400 , (c) 500 and (d) $600{ }^{\circ} \mathrm{C}$ are shown in Fig. 4. The micrograph of the precursor exhibited a dense 

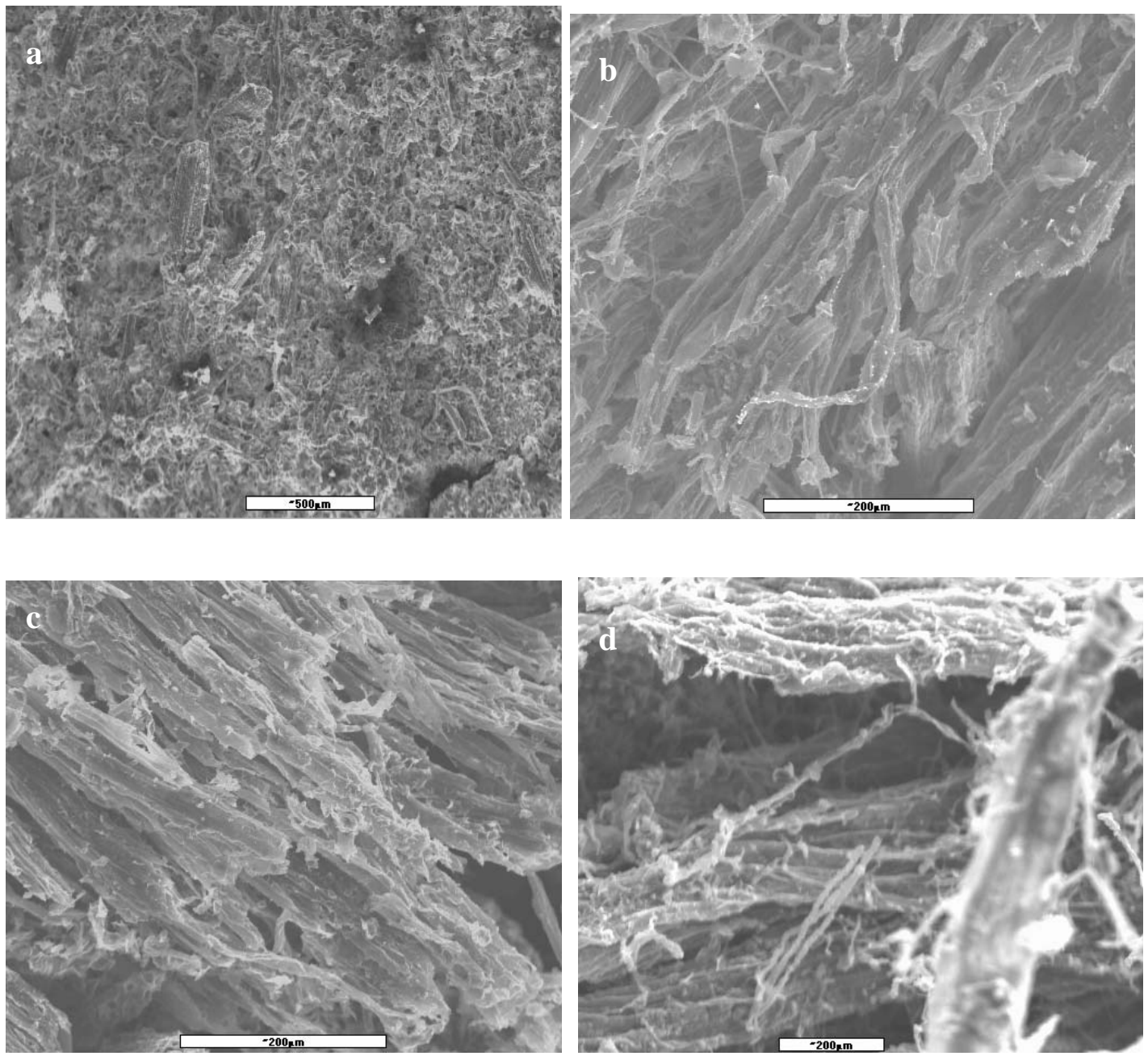

Figure 4. SEM micrographs of Date palm stem chars produced at different temperatures: (a) precursor (as is), (b) $400^{\circ} \mathrm{C}$ (c) $500^{\circ} \mathrm{C}$, (d) $600^{\circ} \mathrm{C}$

structure and smooth surface. The chars show irregular and flaky texture. Interconnecting large pores that increase with the temperature could be observed. This suggests the increase in the release of the volatile compounds from the samples, in line with the increase in the true density. The surface textures were changed when the chars were subjected to $\mathrm{H}_{3} \mathrm{PO}_{4}$ and $\mathrm{KOH}$ (Fig. 5). The texture became denser (higher for acid treated - Fig. 5(a-c), than base-treated samples - Fig. 5(d-f)) and exhibited pores of different sizes and shapes. This indicates the chemical effects on the samples or physical washing of organic matter from the surface. The base-treated samples exhibited grey particles covering the surface. Acid and base impregnation before carbonization resulted into more observable porous surface (Fig. 6 a-c (acid) and d-f (base)). Again, pores of different sizes and shapes could be observed. The higher surface area of samples (Fig. 6b) than that of (Fig. 6c) could be related to the fact that heating above $500{ }^{\circ} \mathrm{C}$ destroyes the tiny pores structure and therefore reduces the available surface area. The smaller pore perimeters of samples in Fig. 6d-f than that of Fig. 6a-c suggest that the chemical washing done by the acid is superior to the one done by the base which might have led to higher surface area. The acid-impregnated samples exhibited surface area an order of magnitude higher than the base treated ones. The base treatment resulted into interaction that produced porous surface, with shallow pores, as indicated by the SEM images.

Surface areas and porosities for the treated carbons are summarized in Table 1. The surface area increases and the average pore diameter decreases with temperature. Carbonized Date palm stems are characterized by poorly developed porous structures of low surface area $(0-119$ $\left.\mathrm{m}^{2} / \mathrm{g}\right)$, low pore volumes $\left(0.00126-0.0839 \mathrm{~cm}^{3} / \mathrm{g}\right)$ and medium to large average pore diameter (28.2 - $539.0 \AA$ ). Subsequent acid treatment of chars reduced porosity development with a decreased surface area (0.36-31.5 $\left.\mathrm{m}^{2} / \mathrm{g}\right)$, decrease in the pore volume $(0.0006-0.0326 \mathrm{cc} / \mathrm{g})$ and consequent increase in the mean pore dimension (41.4-104 Å) compared to carbonization. Perhaps inorganic materials started to react at lower temperature but on heat treatment to higher temperature when the pores were being reorganized; inorganic materials might have filled or blocked some portion of the macropores (Lua, et al. 2004). Activation with phosphoric acid and then carbonization at $500{ }^{\circ} \mathrm{C}$ led to the best porous product with surface area of $1100 \mathrm{~m}^{2} / \mathrm{g}$, internal porosity of $1.15 \mathrm{~cm}^{3} / \mathrm{g}$ and a mean pore dimension of $41.6 \AA$. It can be observed 
The Journal of Engineering Research Vol. 5, No.1 (2008) 47-54
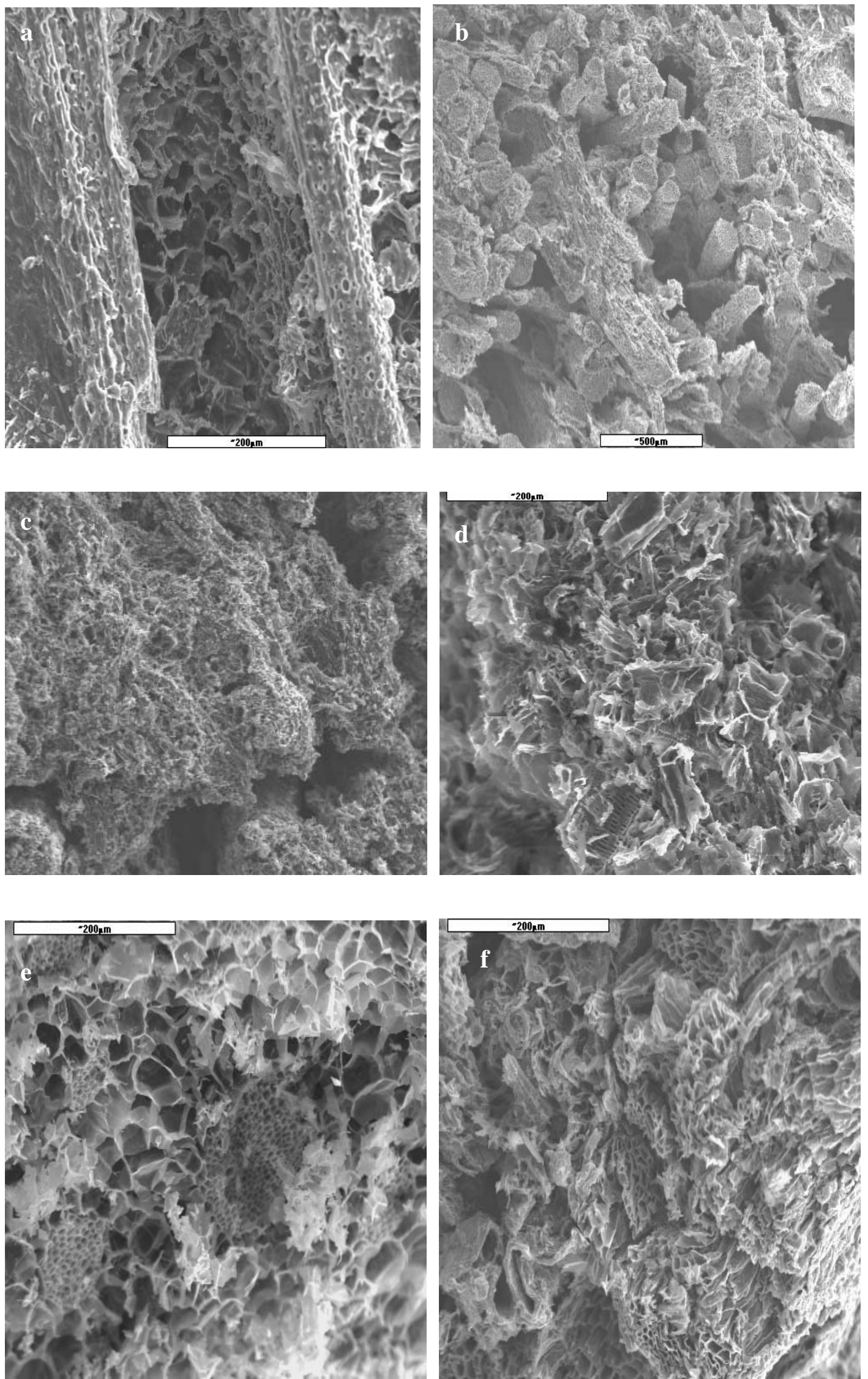

Figure 5. SEM micrographs of chars produced at different temperature and subjected for either $\mathrm{H}_{3} \mathrm{PO}_{4}$ or KOH: (a) S-400-acid, (b) S-500-acid, (c) S-600-acid (d) S-400 base, (e) S-500-base, (f) S-600-base 

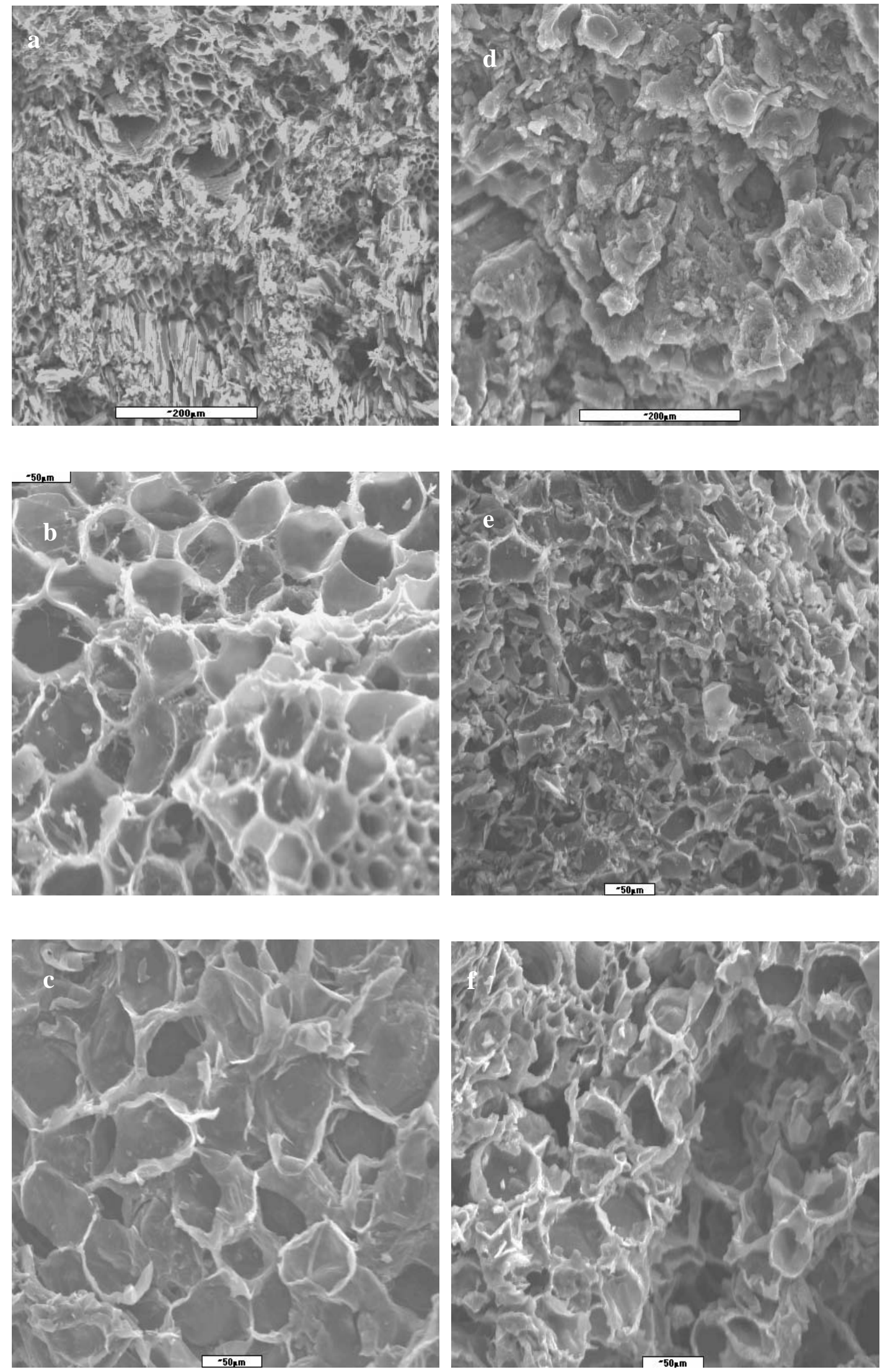

Figure 6. SEM micrographs of chars produced by subjecting the precursor to either H3PO4 or $\mathrm{KOH}$ and then carbonized at different temperature: (a) S-acid-400, (b) S-acid-500, (c) S-acid-600, (d) S-base-400, (e) S-base-500, (f) S-base-600 
that activation with phosphoric acid and then carbonization showed superiority under all treatments. The improvement in surface characteristics when comparing phosphoric acid activation to carbonization were very highly significant; also phosphoric acid activation resulted in a highly significant improvement over potassium hydroxide activation.

The results showed that the Date palm stem chars consist mainly of macropores and mesopores at low treatment temperature.

This result may be further discussed based on the fact that the proportion of a particular porosity generated in the active carbon depends on the preparation conditions, natural and chemical composition of the precursor (Plante, et al. 1988). The conversion of cellulose material to solid carbon yields porous carbon. The porosity depends on the original anatomy of the precursor. The activation treatment given; either by heat treatment or by chemicals results in the formation of surface oxygen complexes. This also results in the increase in the aromaticity of carbon surface due to cross-linking and polymerization of organic molecules, removal of volatiles and opening of blocked pores as the heat treatment temperature is raised (Kidena, et al. 2004). During the process of activation, the spaces between the elementary crystallites become cleared of various carbonaceous compounds. This complex and different degrees of physical and chemical changes in the sample led to similarly irregular surface area, porosity and texture of the samples.

\section{Conclusions}

Porous activated carbon adsorbent has been prepared from Date palm trees. High carbon yield was observed. The products exhibited dominance of meso and macropores, especially at low carbonization temperature (400 $500^{\circ} \mathrm{C}$ ). Generally, phosphoric acid treated precursor yielded higher porosity. A surface area of $1100 \mathrm{~m}^{2} / \mathrm{g}$ was obtained from the precursor impregnated with $\mathrm{H}_{3} \mathrm{PO}_{4}$ and carbonized at $500{ }^{\circ} \mathrm{C}$. The study has shown that Date palm trees stem could be used as raw material for the preparation of activated carbon with good surface properties. More investigations are necessary to give further insight into the nature of the surface functional groups and other characteristics of the product.

\section{Acknowledgments}

The financial assistant of Sultan Qaboos University is gratefully acknowledged. We would like to thank Mr. Saif AlMaamari of the College of Science, Sultan Qaboos University, for the SEM analysis.

\section{References}

Al-Rashdi, B., 2004, Preparation of Activated Carbon from Date Palm Stem," Final Year Student Project, Department of Petroleum \& Chemical Engineering, Sultan Qaboos University, Oman.
Attia, A.A., 1997, "Some Surface Properties of Activated Carbons prepared by Gasification with different Gases," Adsorpt. Sci. Technol. Vol. 15, pp. 707-715.

Benaddi, H., Bandosz, T.J., Jagiello, J., Schwarz, J.A., Rouzaud, J.N., Legras, D. and Béguin, F., 2005, "Surface Functionality and Porosity of Activated Carbons obtained from Chemical Activation of Wood," Carbon, Vol. 38, pp. 669-674.

Byrne, E. and Nagle, D.C., 1997, "Carbonization of Wood for Advanced Materials Applications," Carbon, Vol. 35, pp. 259-266.

Cai, Q., Huang, Z.H., Kang, F. and Yang, J.B., 2004, "Preparation of Activated Carbon Microspheres from Phenolic-Resin by Supercritical Water Activation," Carbon, Vol. 42, pp. 775-783.

Carvalho, A.P., Cardoso, B., Pires, J. and Brotas de Carvalho, M., 2003, "Preparation of Activated Carbons from Cork Waste by Chemical Activation with KOH," Carbon, Vol. 41, pp. 2873-2876.

Caturla, F., Molina Sabio, M. and Rodríguez-Reinoso, F., 1991, "Preparation of Activated Carbon by Chemical Activation with $\mathrm{ZnCl}_{2}$," Carbon, Vol. 29, pp. 9991007.

Daifullah, A.A.M. and Girgis, B.S., 2003, "Impact of Surface Characteristics of Activated Carbon on Adsorption of BTEX," Physicochem Eng. Asp. Vol. 214, pp. 181-193.

Gergova, K. and Eser, S., 1996, "Effects of Activation Method on the Pore Structure of Activated Carbons from Apricot Stones," Carbon, Vol. 34, pp. 879-888.

Girgis, B.S. and El-Hendawy, A.A., 2002, "Porosity Development in Activated Carbons Obtained from Date Pits under Chemical Activation with Phosphoric Acid," Micro. Meso. Mater. Vol. 52, pp. 105-117.

Jagtoyen, M., Thwaites, M., Stencel, J., McEnaney, B. and Derbyshire, F., 1992, "Adsorbent Carbon Synthesis from Coals by Phosphoric Acid Activation," Carbon, Vol. 30, pp. 1089-1096.

Kidena, K., Matsumoto, M., Katsuyama, S., Murata, S. and Nomura, M., 2004, "Development of Aromatic Ring Size in Bituminous Coals during Heat Treatment in the Plastic Temperature Range,” Fuel Proc. Techn. Vol. 85, pp. 827-835.

Liou, T.H., 2004, "Evolution of Chemistry and Morphology during the Carbonization and Combustion of Rice Husk," Carbon, Vol. 42, pp. 785794.

Lua, A.C. and Yang, T., 2004, "Effects of Vacuum Pyrolysis Conditions on the Characteristics of Activated Carbons Derived from Pistachio-Nut Shells," J. Coll. Interface Sci. Vol. 276, pp. 364-372.

Luehrs, D.C., Rogers, T.N. and Godbole, K.A., 1998 "Partition Coefficients of Organic Solutes between Water and Activated Carbon," Encyclopedia of Environmental Analysis and Remediation, Meyers RA, (ed): John Wiley \& Sons. pp 3404-3415.

Molina-Sabio, M., RodRíguez-Reinoso, F., Caturla, F. and Sellés, M.J., 1995, "Porosity in Granular Carbons Activated with Phosphoric Acid," Carbon, Vol. 33, pp. $1105-1113$. 
Nagano, S., Tamon, H., Adzumi, T., Nakagawa, K. and Suzuki, T., 2000, "Activated Carbon from Municipal Waste," Carbon, Vol. 38, pp. 915-920.

Pelekani, C. and Snoeyink, V.L., 2000, "Competitive Adsorption between Atrazine and Methylene Blue on Activated Carbon: the importance of pore size distribution", Carbon, Vol. 38, pp. 1423-1436.

Plante, P., Roy, C. and Chornet, E., 1988, " $\mathrm{CO}_{2}$ Gasification of Wood Charcoals Derived from Vacuum and Atmospheric Pyrolysis," Can. J. Chem. Eng. Vol. 66, pp. 307-312.

Shih, C.C. and Chang, J.R., 2005, "Genesis and Growth of Platinum Subnano-Particles on Activated-Carbon Characterized by X-ray Absorption Spectroscopy: Effects of Preparation Conditions," Mater. Chem. Phy, Vol. 92, pp. 89-97.
Teng, H., Sheng Yeh and Li-Y Hsu, 1998, "Preparation of Activated Carbon from Bituminous Coal with Phosphoric Acid Activation,” Carbon, pp. 1387-1395.

Wartelle, L., Marshall, W., Toles, C. and Johns, M., 2000, "Comparison of Nutshell Granular Activated Carbons to Commercial Adsorbents for the Purgeand-Trap Gas Chromatographic Analysis of Volatile Organic Compounds," J. Chrom. A, Vol. 879, pp. 169-175.

Wigmans, T., 1989, "Industrial Aspects of Production and use of Activated Carbons," Carbon, Vol. 27, pp. 1322.

Yalçın, N. and Sevinç, V., 2000, "Studies of the Surface Area and Porosity of Activated Carbons prepared from Rice Husks," Carbon, Vol. 38, pp. 1943-1945. 